\title{
Authors' Reply to Ulrich: Comment on 'Monoamine Oxidase Inhibitors (MAOIs) in Psychiatric Practice: How to Use Them Safely and Effectively'
}

\author{
David S. Baldwin ${ }^{1} \cdot$ Samuel R. Chamberlain ${ }^{1}$
}

Accepted: 18 November 2021 / Published online: 7 December 2021

(C) The Author(s), under exclusive licence to Springer Nature Switzerland AG 2021

We thank Dr. Ulrich for his positive comments [1] on our recent review article on the place of monoamine oxidase inhibitors (MAOIs) in psychiatric practice [2]. His clear account of the metabolic pathway of endogenous melatonin is instructive, as is his observation that the increase in melatonin plasma levels following tranylcypromine administration results from increased availability of serotonin (a melatonin precursor) and noradrenaline (a melatonin activator), rather than from the inhibition of melatonin metabolism [3].

Dr. Ulrich cites an earlier personal publication focused on tranylcypromine pharmacology and efficacy in depression [4]. That article cites estimates of the risk of severe cerebrovascular complications after tyramine hypersensitive reactions with the drug as either $0.007 \%$, or 50 cases from 3.5 million patients, or six cases from 102,000 patients. These figures equate to an estimated incidence lying between 1.43 and 7.0 per 100,000 patients (and not the erroneous figure of between 140 and 700 per 100,000 patients as written in our article). We regret this simple error in our mathematical calculation and correct this in a published Correction notice [5]. We wish to reiterate that whilst the risk of such reactions with tranylcypromine is indeed very low (and unlikely to be encountered in routine clinical practice), patients should still be advised to follow the recommended dietary restrictions whilst taking traditional MAOI drugs.

This reply refers to the comment available online at https://doi.org/ 10.1007/s40263-021-00881-2.

David S. Baldwin

dsb1@ soton.ac.uk

1 University Department of Psychiatry, Clinical and Experimental Sciences (CNS + Psychiatry), Faculty of Medicine, University of Southampton, College Keep, 4-12 Terminus Terrace, Southampton SO14 3DT, UK

\section{Declarations}

Funding SRC is funded by a Clinical Fellowship from the Wellcome Trust (reference 110049/Z/15/Z and 110049/Z/15/A).

Conflict of interest DSB is President-Elect of the BAP and a medical patron of Anxiety UK. He receives stipends from Wiley for editorial work relating to the journal Human Psychopharmacology. SRC previously consulted for Promentis on work not related to MAOIs. He receives honoraria from Elsevier for editorial work at the journals $\mathrm{Neu}$ roscience and Biobehavioral Reviews and Comprehensive Psychiatry.

Ethics approval Not applicable.

Consent to participate Not applicable.

Consent for publication Not applicable.

Availability of data and materials Not applicable.

Code availability Not applicable.

Author contributions DSB and SRC contributed equally in drafting this reply.

\section{References}

1. Ulrich S. Comment on 'Monoamine oxidase inhibitors (MAOIs) in psychiatric practice: how to use them safely and effectively'. CNS Drugs. 2021. https://doi.org/10.1007/s40263-021-00881-2.

2. Chamberlain SR, Baldwin DS. Monoamine oxidase inhibitors (MAOIs) in psychiatric practice: how to use them safely and effectively. CNS Drugs. 2021;35:703-16.

3. Oxenkrug GF, Balon R, Jain AK, McIntyre IM. Melatonin plasma response to MAO inhibitor: influence on human pineal activity? Acta Psychiatr Scan. 1988;77(2):160-2.

4. Ricken R, Ulrich S, Schlattmann P, Adli M. Tranylcypromine in mind (Part II): review of clinical pharmacology and meta-analysis of controlled trials in depression. Eur Neuropsychopharmacol. 2017;27(8):714-31.

5. Chamberlain SR, Baldwin DS. Correction to: Monoamine oxidase inhibitors (MAOIs) in psychiatric practice: how to use them safely and effectively. CNS Drugs. 2021. https://doi.org/10.1007/ s40263-021-00880-3. 